\title{
PENGGUNAAN SOLAR COLLECTOR SEBAGAI PEMANAS AWAL AIR MASUK DAN PEMANAS TAMBAHAN BAWAH HEAT ABSORBER PADA BASIN SOLAR STILL UNTUK MENINGKATKAN EFISIENSI
}

\author{
M. Syafwansyah Eff(1), Ahmad Hendarawan ${ }^{(1)}$ Noor Rahman $^{(1)}$ \\ msyafwansyah@gmail.com, ahendra 72@yahoo.com, nunur77@yahoo.com
}

(1) Staf Pengajar Progam Studi Teknik Alat Berat Politeknik Negeri Banjarmasin

\begin{abstract}
All basin solar still in general use under the askew glass cover as condensation media to place the condensate flows toward the lower sections with use gravitation. It is known that when condensation occurs release considerable heat energy to environment. Solve this problem, in this research is to minimize the loss of substantial energy, utilizing the heat from the solar collector. Heat is supplied to the bottom of the heat absorber and heat exchanger. Research methods is experiment. In this research is examine both the prototype, that is basin solar still with solar collector and basin solar still without solar collector. The measured parameter is temperature button section heat absorber, outside heat absorber, button section of glass cover, condensate water, environment, solar collector, heat exchanger and soar radiation.

In this result temperature average at button section heat absorber is $47,03^{\circ} \mathrm{C}$ for prototype with solar collector and without solar collector is $45,25^{\circ} \mathrm{C}$. Solar radiation average is 304,11 $\mathrm{W} / \mathrm{m}^{2}$. Efficiency both prototype is $29,45 \%$ with solar collector and $19,86 \%$ without solar collector. By comparing efficiency two prototype is concluded that the Solar Collector as preheater water and additional heating of water under heat absorber $67.45 \%$ better than that without using Solar Collector.
\end{abstract}

Keywords : Solar Collector, Heat Absorber, Heat Exchanger, Efficiency

\section{PENDAHULUAN}

\section{Latar Belakang}

Laju konsumsi air bersih di dunia meningkat dua kali lipat setiap 20 tahun, melebihi dua kali laju pertumbuhan manusia. Beberapa pihak memperhitungkan bahwa pada tahun 2025, permintaan air bersih akan melebihi persediaan hingga mencapai 56\% (Shofinita, 2009 dalam Safitri, 2011). Di sisi lain, pencemaran air permukaan (sungai dan danau) yang disebabkan oleh limbah industri dan pertanian serta limbah domestic dalam jumlah besar membatasi ketersediaan sumber air bersih (Fath, et al., 2008).

Sumber air yang secara kuantitas tidak terbatas adalah air laut, namun kualitasnya sangat buruk karena mengandung kadar garam atau TDS (Total Dissolved Solid) sangat tinggi (Yuan, et al., 2011). Untuk mengatasi masalah tersebut, salah satu caranya adalah dengan menerapkan teknologi pengolahan air laut. Proses pengolahan air laut menjadi air tawar tersebut dikenal sebagai proses desalinasi (Deng, et al., 2010).

Seluruh proses desalinasi jelas memerlukan energi untuk menyisihkan garam dari air laut. Jika desalinasi dilakukan dengan teknologi konvensional akan memerlukan pembakaran bahan bakar fosil dalam jumlah besar (produksi air bersih sebesar $1000 \mathrm{~m}^{3} /$ hari memerlukan 10.000 ton minyak per tahun), sementara ketersediaan bahan bakar tersebut semakin berkurang, maka diperlukan sumber energi lain, salah satunya adalah pemurnian air laut dengan tenaga matahari (Yilmaz dan Soylemez, 2012). Hal ini didasari bahwa tenaga matahari merupakan renewable energy (energi terbarukan), aman, gratis, dan bebas polusi (tanpa emisi CO2). Tenaga matahari merupakan solusi yang menjanjikan untuk menghemat biaya. Selain itu, Indonesia merupakan Negara yang memiliki intensitas matahari yang berlimpah, yaitu rata - rata $4,8 \mathrm{kWh} / \mathrm{m} 2$.hari (Astawa, 2008).

Selanjutnya menurut prediksi Badan Pusat Statistik (BPS) bahwa pada 2015 jumlah penduduk Indonesia melonjak menjadi 247,5 juta jiwa. Pertambahan penduduk tersebut berbanding lurus dengan kebutuhan air, dan diprediksi menjadi 9.391 miliar $\mathrm{m}^{3}$ atau naik 47 persen dari tahun 2000. Padahal ketersediaan air cenderung menurun setiap tahunnya, salah satu kasus didaerah padat penduduk (Pulau Jawa), 
ketersediaan air hanya $1.750 \mathrm{~m}^{3}$ per kapita per tahun, jauh di bawah standar kecukupan yaitu $2.000 \mathrm{~m}^{3}$ per kapita per tahun. Permasalahan ini apabila tidak ditanggulangi , dipastikan Indonesia akan mengalami kelangkaan air bersih pada 2015. Diperkirakan, ketersediaan air pada tahun tersebut hanya $1.200 \mathrm{~m}^{3}$ per kapita per tahun. (Agustiar,2007)

\section{Penelitiaan-penelitian sebelumnya}

Jackson dan Van Bavel (1965) mengusulkan suatu peralatan penyulingan sederhana, terdiri dari rangka kayu segi empat yang bagian samping dan atasnya ditutup dengan kaca. Permukaan tanah merupakan dasar dari peralatan, dengan demikian peralatan dapat digunakan di atas tanah yang basah akibat hujan serta air buangan. Hasil maksimum yang didapat dari peralatan ini hanya $1,5 \mathrm{liter} / \mathrm{m}^{2} /$ hari.

Lawrence dan Tiwari (1990) meneliti, ada faktor yang sangat berpengaruh pada jumlah intensitas radiasi matahari, yaitu letak geografis suatu tempat. Tidak semua tempat di suatu wilayah memiliki intensitas radiasi matahari yang sama.

Delyanis dan Belessiotis (2001) dan Kharabsheh dan Goswani (2003), mengemukakan salah satu alasan utama yang melatar belakangi rendahnya efisiensi solar stiil (peralatan pemurnian air tenaga surya) karena sekitar 30-40\% adalah kehilangan panas laten kondensasi kelingkungan dan panas laten yang terbuang oleh kondensat.

Nita (2004) menambahkan bahan batu kerikil diameter $1 \mathrm{~cm}$ sebagai heat absorber, dari hasil pengamatan diperoleh bahwa adanya batu kerikil akan menambah luas permukaan penguapan dan pemantulan radiasi matahari secara acak. Selain itu akan menambah volume penyimpanan energi panas oleh solar still.

Handoyo (2002), penelitian yang dilakukkan adalah mengenai pengaruh jarak kaca dan heat absorber terhadap panas yang diterima solar still. Dalam penelitiannya ini, radiasi matahari terbesar yang mampu diteruskan adalah pada jarak kaca dengan heat absorber sejauh $20 \mathrm{~cm}$.

Hirmawan dkk (2009) Melakukan penelitian guna memecahkan permasalahan penye-diaan air tawar (air bersih) di kawasan pesisir, yang dalam penelitian ini lokasi dilakukan di kawasan Pantai Paranggupito Kabupaten Wonogiri, melalui proses destilasi air laut menjadi air tawar dengan menggunakan energi panas yang berasal dari energi surya dan pembakaran sekam padi.
Bahan baku yang digunakan dalam penelitian ini adalah kerikil, pasir laut dan arang, sementara peralatan utama yang digunakan dalam penelitian ini adalah distilator bersistem kolektor pelat datar dengan bahan kolektor divariasi dengan tiga material (kerikil, pasir laut, arang). Hasil penelitian menunjukkan bahwa desain distilator air laut terbaik sesuai hasil penelitian adalah distilator dengan kolektor panas terbuat dari arang dan dengan sistem 2 lapis kaca bertenaga surya, dimana dengan distilator ini dapat menghasilkan uap air $9,58 \%$ sampai dengan $53,3 \%$ dari air laut umpan dan mampu mengembunkan 16,3\% sampai dengan $42,1 \%$ potensi uap air tersebut.

Taufik Akhirudin (2007) melakukan penelitian dengan tujuan mengetahui dan membandingkan produktivitas dari tiga desain alat distilator air laut berbasis tenaga surya, menentukan produktivitas terbaik dari tiga desain alat distilator berbasis tenaga surya, menentukan faktor-faktor yang mempengaruhi produktivitas alat, mengetahui kualitas air yang dihasilkan dari proses kerja alat destilasi air laut berbasis tenaga surya. Hasil yang didapatkan adalah Kualitas air yang dihasilkan memiliki salinitas nol, parameter warna 0,432 0,787 Unit PtCo, kekeruhan 0,4-2,0 NTU, nilai $\mathrm{pH}$ 7,8-8,2, rasa tawar (normal) dan bau normal (tidak berbau). Hasil uji kualitas air telah memenuhi syarat standar air minum menurut SNI 01-3553-1996.

Mulayanet dkk (2006) melakukan penelitian pada distilator basin type solar still dengan tujuan untuk menentukan tipe kaca penutup kolektor yang sesuai untuk dipasang pada peralatan destilasi air laut jenis tersebut. Dari hasil penelitiannya didapatkan bahwa tipe penutup kolektor plat datar tipe dua permukaan miring menghasilkan kondensat terbanyak sebesari $255 \mathrm{ml} / \mathrm{jam}$ dengan intensitas surya tertinggi $757,37 \mathrm{~W} / \mathrm{m}^{2}$.

Syafwansyah dkk (2012) meneliti pengaruh penggunaan preheater pada basil solar still tipe penutup miring terhadap efisiensi, berhasil menngkatkan efisiensi 1,667 \% dibandingkan dengan tanpa preheater.

Syafwansyah dkk (2015) mendesain destilator basin type solar still yang dilengkapi dengan solar collector sebagai pemanas awal dan pipa kondensat sebagai heat recovery, berhasil menaikan efisiensi basin sebesar $33,268 \%$.

\section{Hipotesa}

Dari hasil-hasil penelitian terdahulu permasalahan yang mendasar pada basin solar still adalah berapa besar efisiensinya 
dari model-model yang dikembangkan. Salah satu hasil penelitian ini yang telah dikembangkan oleh penulis adalah dengan menambahkan solar collector sebagai pemanas awal dan pipa kondensat sebagai heat recovery dan hasilnya menang terjadi peningkatan dari efisiensi dibandingkan dengan yang tanpa penambahan peralatan tersebut. Hal ini memunculkan sebuah usulan baru, yaitu bagaimana kalau solar collector ini diperbaiki desainnya dan dimaksimalkan fungsinya tidak saja sebagai pemanas awal tapi juga difungsikan untuk memanaskan air bawah heat absorber menggantikan fungsi atau membantu pipa kondensat sebagai heat rocovery. Dengan penambahan ini diyakini bahwa akan terjadi peningkatan efisiensi yang lebih baik, untuk ini perlu menguji prototipe ini.

\section{Tujuan}

Tujuan dari penelitian ini adalah menguji seberapa besar efisiensinya dengan menambahkan solar collector yang sudah diperbaiki tidak saja sebagai pemanas awal tapi juga panasnya ditrasfer ke bagian bawah heat absorber. Luaran dari penelitian ini adalah menghasilkan suatu prototipe basin solar still dengan indikator performance yang lebih baik dari sebelumnya serta tekonologi tepat guna yang bisa dimanfaatkan untuk pengolahan air bersih.

\section{METODE PENELITIAN}

\section{Konsep Dasar}

Pada rencana penelitian berikut ini adalah mengembangkan destilator surya dengan memaksimalkan fungsi dari solar collector tidak saja sebageai pemanas awal, tapi juga berfungsi sebagai penjaga panas pada bagian bawah heat absorber. Hal ini dengan tujuan yang sama meningkatkan efisiensi dari destilator. Pemaksimalan fungsi dari solar collector ini adalah dengan jalan menggunakan solar collector yang fungsinya memanaskan air sebelum masuk ke basin, tapi juga panas dari collector akan dipindahkan dengan saluran pemindah panas dengan menggunakan fluida pemindah panas seperti oli, atau metanol. Di samping itu juga menyempurnakan desain dari solar collector sendiri.

\section{Pengukuran Variabel}

Pengujian dilakukan secara bersamaan pada Basin Solar Still yang dilengkapi dengan heat exchanger dan preheater dan tanpa heat exchanger dan preheater pada kondisi yang yang sama. Pengujian dilakukan mulai jam 09 sampai dengan jam 17.00 dan mencatat setiap 15 menit variabel yang diukur. Variabel yang diukur dalam penelitian in volume produksi kondensat, tempetur permukaan kaca basin, air bawah absorber, air kondensat, heat absorber, heat exchanger dan radiasi matahari.

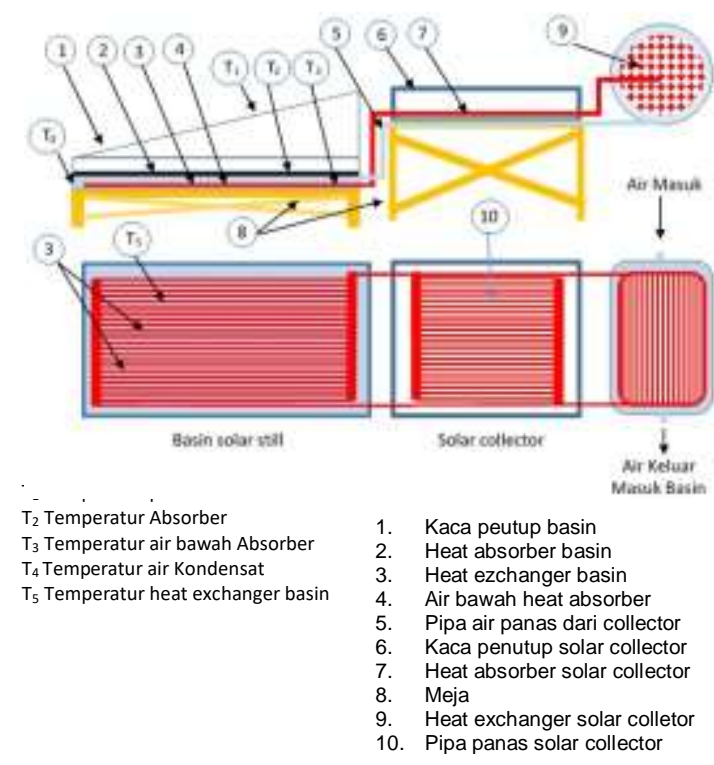

Gambarr 1. Rancangan Protoripe

\section{Pengukuran Variabel}

Pengujian dilakukan secara bersamaan pada Basin Solar Still yang dilengkapi dengan heat exchanger dan preheater dan tanpa heat exchanger dan preheater pada kondisi yang yang sama. Pengujian dilakukan mulai jam 09 sampai dengan jam 17.00 dan mencatat setiap 15 menit variabel yang diukur. Variabel yang diukur dalam penelitian in volume produksi kondensat, tempetur permukaan kaca basin, air bawah absorber, air kondensat, heat absorber, heat exchanger dan radiasi matahari

\section{HASIL DAN PEMBAHASAN}

\section{Grafik Hasil Pengujian Basin Solar Stil}

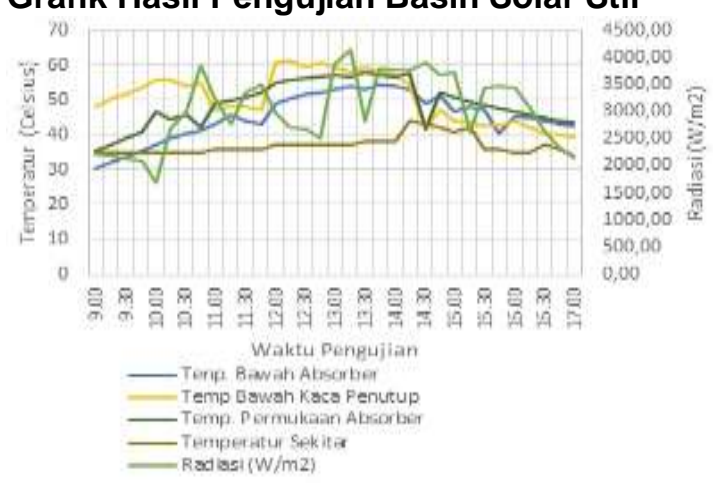

Gambar 2. Grafik Tanpa Solar Collector 


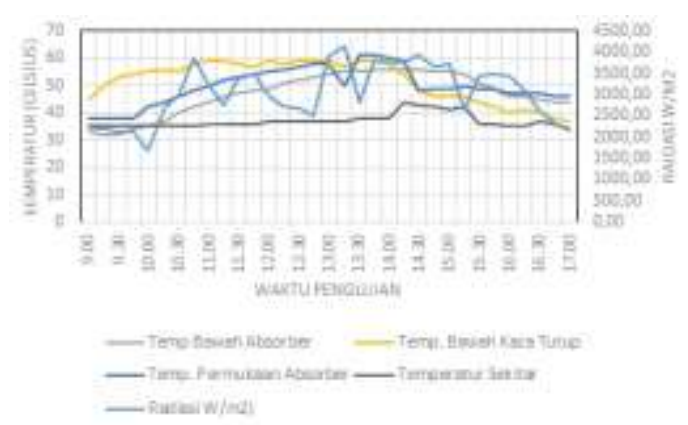

Gambar 3. Grafik Dilengkapi Solar Collector

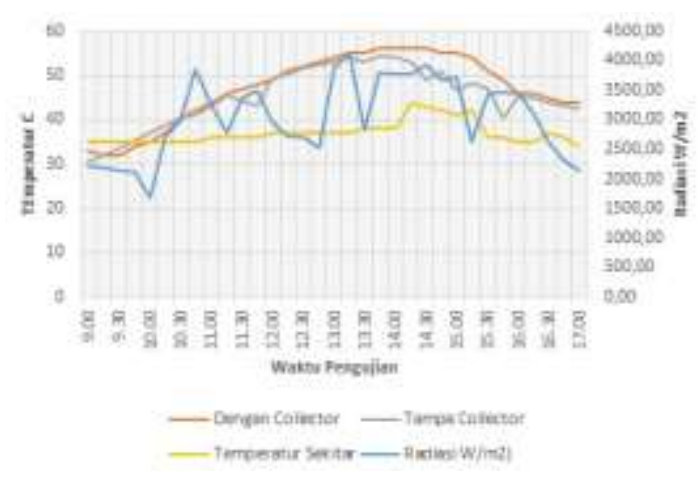

Gambar 4. Grafik Perbandingan Temperatur Bawah Absorber

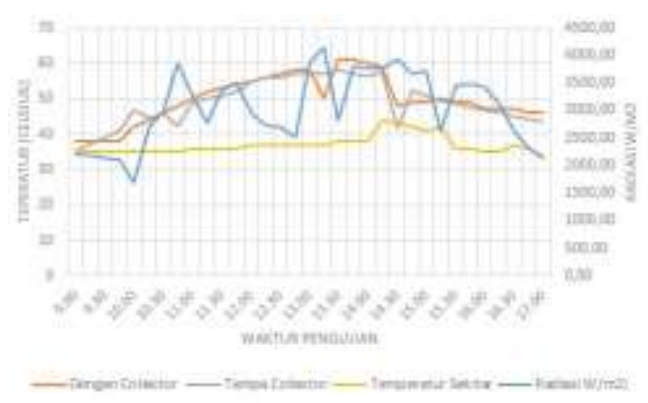

Gambar 5. Grafik Perbandingan Temperatur Atas Absorber

Dari hasil pengujian kedua basin terlihat bahwa temperatur bawah absorber (Gambar.4) yang dilengkapi dengan solar collector sebagai pemanas bawah absorber lebih tinggi dari pada yang tanpa menggunakan. Temperatur bawah absorber cukup penting untuk menjaga panas air yang masuk tetap tinggi, sehingga tidak membutuhkan penyerapan energi matahari yang terlalu lama untuk menjadi air menjadi kondensat. Pada hasil pengujian temperatur atas absorber (Gambar 5) hampir tidak terlalu berbeda jauh dari yang menggunakan solar collector dengan yang tanpa menggunakan. Efisiensi Basin

\section{Tabel 1. Perbandingan Efisiensi}

\begin{tabular}{|c|l|c|c|c|}
\hline No & Basin & $\begin{array}{c}\mathrm{hg} \\
(\mathrm{kJ} / \mathrm{kg})\end{array}$ & $\begin{array}{c}\text { Produksi } \\
\text { Kondensat }\end{array}$ & $\begin{array}{c}\mathrm{N} \\
(\%)\end{array}$ \\
\hline 1 & Dengan Collector & 2.382 & 0,67 & 0,294 \\
\hline 2 & Tanpa Collector & 2.392 & 0,45 & 0,198 \\
\hline
\end{tabular}

\section{KESIMPULAN}

Efisiensi tertinggi dengan penggunaan solar collector sebagai pemanas bawah absoer pada basin type solar still sebesar $29,45 \%$ sedangkan efisiensi tertinggi pada basin type solar still tanpa menggunakan soar collector $19,86 \%$ jadi terjadi peningkatan efisiensi peralatan sebesar $67,45 \%$. Peningkatan ini akibat adanya penambahan kenaikan temperatur bawah absorber yang mampu mempertahankan panas air pada basin.

\section{DAFTAR PUSTAKA}

[1] Agustiar, D.R., 2007, Indonesia Terancam Kekurangan Air Bersih, Tempo interaktif.com,

http://www.tempointeraktif.com diunduh pada tanggal 12 Februari 2012

[2] Astawa Ketut, 2008, Pengaruh Penggunaan Pipa Kondensat Sebagai Heat Recorvery Pada Basin Type Solar Still Terhadap Efisiensi, Jurnal IImiah Teknik Mesin Cakram, Vol 2, No.1, 34-41

[3] Delyanis, E dan Belessiotis V., 2001, Solar Energy and Desalination, Advances in Solar Energy, An Annual Review of Research and Depolepment. D.Y. Goswami, Ed., Vol 14, Amerecan Solar Energy Society, Boulder Clorado

[4] Deng, R., Xie, L., Lin, H., Liu, J., Han, W. 2010. Integration of Thermal Energy and Seawater Desalination. Energy 36 (2010) 4368-4374

[5] Fath, H.E.S., Elsherbiny, S.M., Hassan, A.A., Rommel, M., Wieghaus, M., Koschikowski, J., Vatansever, M. 2008. PV and Thermally Driven Small Scale, Stand Alone Solar Desalination Systems with Very Low Maintenance Needs. Desalination 225 (2008) 58-69.

[6] Handoyo A.E., 2002, Pengaruh Jarak Kaca ke Heat Absorber Terhadap Panas yang diterima Suatu Heat Absorber, 
Jurnal Teknik Mesin Universita Kristen Petra, Vol 4, No.1.

[7] Hermawan, Dwi Aries, Supriyadi, 2009, Destilasi air laut menjadi air tawaar dengan memanfaatkan energi surya dan pembakaran sekam padi di Paranggupito Kabupaten Wonogiri. http://www.Ippm.uns.ac.id,Feb, 25,2010

[8] Jackson R.R., Van Bavel C.H.M., 1965, Solar Distillation of Water from Soil and Plant Material, a Simple Desert Survival Tecnique Science, 149, Holand

[9] Lawrence S.A., Tiwari, GN,. 1990, Theorical Evaluation of Solar Distillation Under Natural Circulation with Heat Exchanger, Energy Conv. Management America

[10] Mulyanet, dkk Sistem Distgilasi Air Laut Tenaga Surya Menggunakan Kolektor Plat Datar Dengan Tipe Kaca Penutup Miring, 2006 http://noviwidi.blog.uns.ac.id/files/2010/05/sistem distilasi a ir laut tenaga $s$

urya menggunakan kolektor plat .pdf , Mei, 15,2010.

[11] Nita C.V., Sudjito, 2004, Usaha-usaha Untuk Meningkatkan Efisiensi dan Produktivitas Solar Still, Jurnal Publikasi IImiah Program Pascasarjana Universitas Brawijaya Malang

[12] Syafwansyah M Effendi dkk, 2012, Pengaruh Penggunaan Preheater pada Basin Type Solar Still Dengan Tipe Kaca Penutup Miring Terhadap Efisiensi, Jurnal IImiah Pengetahuan dan Penerapan Teknik Industri Spektrum Industri, Volume 10 Nomor 2, 122 - 133

[13] Syafwansyah M Effendi, Hendrawan Ahmad, Rahman Noor, 2015, Penggunaan Solar Collector Sebagai Pemanas Awal dan Pipa Kondensat Sebagai Heat Recovery Pada Basin Solar Still Untuk Meningkatkan Efisiensi, Seminar Nasional Tahunan Teknik Mesin Indonesia XIV, 7-8 Oktober 2015, Banjarmasin.

[14] Safitri, Mifta Ardianti. 2011. Penelitian Kualitas dan Kuantitas Air Destilat dengan Pengembangan Multiple Trays Tilted Still (Studi: Penambahan Kolektor Kain Hitam). Tugas Akhir Program Sarjana Teknik Lingkungan ITB
[15] Taufik Akhirudin , 2007, Desain Alat Destilasi Air Laut Berbasis Tenaga Surya Sebagai Alternatif Penyedian Air Bersih, ile:///E:/Download/desain-alat-destilasiair-laut-berbasis.html, Mei,27,2010

[16] Yuan, G., Wang, Z., Li, H., dan Li, X. 2011. Experimental Study of A Solar Desalination System Based on Humidification-Dehumidification Process. Desalination 277 (2011) 92-98.

[17] Yilmaz, Ibrahim Halil dan Soylemez, Mehmet Sait. 2012. Design and Computer Simulation on Multi-Effect Evaporation Seawater Desalination System Using Hybrid Renewable Energy Sources in Turkey. Desalination 291 (2012) 23-40. 